\title{
¿Utópolis o distópolis?: producción inmobiliaria y metropolización en el litoral central de Chile (1992-2012)
}

\author{
Rodrigo Hidalgo. Pontificia Universidad Católica de Chile, Santiago, Chile. \\ Federico Arenas. Pontificia Universidad Católica de Chile, Santiago, Chile. \\ Daniel Santana. Pontificia Universidad Católica de Chile, Santiago, Chile.
}

RESUMEN | La expansión metropolitana ha asumido en las últimas décadas numerosas formas, funciones y estructuras. En el artículo se analiza el modo en que las amenidades del medio físico en el litoral central de Chile fueron utilizadas entre 1992 y 2012 para promover utópolis, que terminan convirtiéndose en distópolis, por sus impactos socioespaciales. Se identificaron dos fases de este proceso: una de expansión de las segundas residencias y otra de reocupación e instalación de viviendas principales a partir de una mayor integración y del intenso proceso de metropolización que afecta a la macrozona urbana central de Chile.

PALABRAS CLAVE | vivienda, mercado inmobiliario, metropolización, urbanización.

ABSTRACT | Urban sprawl has taken varied forms, functions, and structures in recent decades. The aim of this article is to analyze how production processes of utopolis became distopolis through negative socio-spatial effects in the central coast of Chile between 1992 and 2012. Two stages are identified in the process: an earlier expansion of the secondary housing and another one of building main housing with great spatial integration and a strong process of urban sprawl in the central urban macrozone of Chile.

KEY WORDS | housing, real estate market, metropolization, urbanization.

Recibido el 23 de septiembre de 2014, aprobado el 22 de septiembre de 2015

E-mail: R.Hidalgo, rhidalgd@uc.cl |F.Arenas, farenasv@uc.cl |D.Santana, ldsantana@uc.cl 


\section{Introducción ${ }^{1}$}

La emergencia de la sociedad urbana y la extensión ilimitada del tejido urbano han dejado de ser un objeto para el análisis transductivo, esto es, aquel que aborda lo posible o potencial (Lefebvre, 1980), para hacerse concretos a través de patrones de concentración y dispersión o de explosión e implosión, como lo sugirió el mismo Lefebvre hace varias décadas. Desde la teoría urbana anglosajona, e incluso la latinoamericana, se ha señalado el doble rol -causa y efecto- de la producción capitalista del espacio urbano como catalizador de la urbanización generalizada (Brenner, 2013; De Mattos, 2013; Harvey, 2013; Lencioni, 2011). Tal proceso de producción del espacio, aunque presenta rasgos universales que conforman cierta estructura -la búsqueda de acumulación, las pautas regulatorias, la competencia entre agentes capitalistas, las tendencias a la concentración y centralización del capital, las rentas del suelo urbano y la larga durabilidad como aspectos singulares de las mercancías inmobiliarias (Harvey, 1991)-, se expresa también mediante formas y funciones espaciales muy diversas: se producen múltiples geografías de la urbanización (Brenner, 2013).

Entre los diferentes mecanismos de urbanización y valorización del espacio vigentes en la actualidad, está la venta de productos inmobiliarios caracterizados por condiciones de sitio y situación únicas, circunstancias que permiten generar altas rentas de monopolio y beneficios económicos. De esa manera, espacios con una alta calidad paisajística - montańas, valles, sabanas, bordes costeros y demás- son incorporados al mercado inmobiliario urbano mediante la promoción de utopías vinculadas al disfrute de la naturaleza y de las amenidades, ya sea mediante casas o edificios dispuestos en pequeños condominios cerrados o ciudades valladas, con un valor de uso como residencia principal o secundaria. Estas áreas residenciales implican la emergencia de fenómenos de elitización, exclusión, segregación y degradación ambiental, es decir, la antinomia de la utopía, la distopía ${ }^{2}$. Aunque se venden como utópolis que permiten experimentar el medio natural con condiciones de vida urbana, se concretan como distópolis a partir de sus efectos socioespaciales.

El objetivo del presente artículo es describir cómo la promoción de utópolis y la masificación de las distópolis en el borde costero (Hidalgo \& Arenas, 2012; Hidalgo, Santana \& Villagrán, 2014) se insertan dentro de un amplio e intenso proceso de metropolización que, entre 1992 y 2012, conformó una macrozona urbana en el centro de Chile (Hidalgo, Arenas, Sánchez \& Wolker, 2014). En la primera parte se hace una reflexión teórica acerca de los rasgos generales que caracterizan los procesos metropolitanos y de urbanización litoral, para luego, mediante un método dialéctico de descripción geográfica, caracterizar los aspectos del proceso de ocupación de los bordes costeros en las comunas litorales de la Quinta Región

1 Este trabajo es producto de los proyectos FONDECYT 1095222, "La transformación de las aéreas centrales: reestructuración comercial y elitización (gentrificación) residencial. El caso de Santiago, Valparaíso y Viña del Mar"; y FONDECYT 1120223, "Negocios inmobiliarios y segunda residencia: la ciudad sin límites en las comunas del litoral de la región de Valparaíso (1992-2012)”.

2 Distopía proviene del inglés dystopia, término empleado en ciencia ficción para expresar lo contrario a la utopía. 
de Valparaíso: Algarrobo, Cartagena, Casablanca, Concón, El Quisco, El Tabo, La Ligua, Papudo, Puchuncaví, Quintero, San Antonio, Santo Domingo, Valparaíso, Viña del Mar y Zapallar.

\section{Utopólis y distópolis costeras en un contexto de metropolización y reestructuración inmobiliaria}

La urbanización es un proceso geográficamente desigual que se expresa en fases de concentración urbana -modalidad que predominó en Estados Unidos y Europa hasta antes de la posguerra y en América Latina hasta los años setenta- y de dispersión. Esta última fase, documentada en detalle para los países de capitalismo avanzado (Soja, 2008; Gottdiener, 1994) y denominada como posurbanización por Hidalgo y Borsdorf (2009), ha comenzado a manifestarse en América Latina desde la década de los ochenta, haciéndose más evidente desde comienzos del siglo XXI: en ambos casos -la concentración y la dispersión urbana-, las reestructuraciones contemporáneas del capitalismo actúan como la fuerza motriz principal para la creación destructiva de la ciudad y lo urbano.

Las metrópolis latinoamericanas han experimentado un proceso de creación destructiva de estructuras, formas y funciones urbanas, a partir del giro neoliberal y globalizador que sustituyó al modelo de industrialización por sustitución de importaciones (De Mattos, 2010). Esta nueva fase de metamorfosis metropolitana (Lencioni, 2011) se caracteriza, en términos de formas y funciones espaciales, por el reescalamiento de ciertas ciudades y metrópolis a regiones urbanas (De Mattos, 2013), así como por la creación y renovación de centralidades en áreas ya consolidadas (Hidalgo, 2013; Hidalgo \& Janoschka, 2014), en un doble movimiento de dispersión y concentración de las inversiones inmobiliarias. Dicho reescalamiento en las ciudades latinoamericanas ha sido conceptualizado de manera diversa a partir de nociones tan disímiles como metropolización expandida y fragmentada (De Mattos, 2010), concentración desconcentrada (Cuervo \& González, 1997), transición del proceso urbano (Ciccolella \& Mignaqui, 2009), conglomerados urbano-regionales (Moura, 2011), metropolización del espacio (Lencioni, 2011) o transición metropolitana (Pereira, 2008), por solo enumerar algunas ${ }^{3}$.

Las fuerzas que han producido esa metamorfosis provienen de lo que De Mattos (2013) considera una nueva fase de modernización capitalista, en la cual, mediante la instauración de políticas neoliberales - de desregulación, privatización y mercantilización- y la revolución de las tecnologías digitales de la información, se produjo una compresión espacio-temporal que permitió crear un espacio global de acumulación. De Mattos $(2010,2013)$ caracteriza este proceso a través de distintos rasgos: una mayor desintegración espacial de las fases de producción, promovida por el capital transnacional y destinada a aprovechar las condiciones de valorización diversas; una mayor libertad de movimiento del capital financiero, que facilita la producción; y el consumo de artefactos arquitectónicos genéricos. Su corolario, según el mismo De

De Mattos (2013) hace el mismo ejercicio incluyendo terminología norteamericana y europea. 
Mattos, sería la extensión del campo de externalidades urbanas y la ampliación de alternativas de localización para las familias y empresas.

Tanto la apertura de nuevas localizaciones como el mayor flujo de capital financiero para la producción y consumo de espacio construido, incidieron en una reestructuración del sector inmobiliario en las grandes metrópolis latinoamericanas (Pereira, 2008; Lencioni, 2014). Mediante la mayor disponibilidad de capital financiero, los negocios inmobiliarios se han vuelto extremadamente rentables (Pereira, 2013): se han dado procesos de concentración y centralización del capital inmobiliario (Lencioni, 2014), potenciando economías de escala mediante la operación de macroproyectos (Santana, 2013) que tienden a reducir las largas tasas tradicionales de rotación de las mercancías inmobiliarias. Ello no solo implica una mayor disponibilidad de excedentes para su reinversión productiva en el sector mediante la construcción; también comporta un desmesurado aumento de las perspectivas de acumulación y especulación en dicho sector, ligadas a la conversión de la propiedad en activos financieros transables (Pereira, 2013).

Las estrategias de los agentes inmobiliarios se han orientado hacia la producción de nuevos artefactos arquitectónicos - de la globalización, en términos de De Mattos (2002)-, localizándolos dentro de la ciudad consolidada o en las periferias metropolitanas. Es así como edificios inteligentes, shoppings centers, parques industriales en las periferias metropolitanas, privatópolis (sean pequeńos condominios o ciudades valladas), e incluso precariópolis (viviendas sociales producidas bajo lógicas público-privadas, según Hidalgo, Borsdorf \& Zunino, 2008), han ido construyendo la ciudad de principios del siglo xxi en América Latina. Entre aquellos artefactos, aunque uno no tan novedoso, están las segundas residencias, que han experimentado un proceso de masificación paralela a la del turismo y el ocio. De esta forma, mediante su localización ya sea en áreas no urbanas y poco articuladas a una ciudad o en ciertos enclaves de las crecientes regiones metropolitanas, han contribuido a extender tanto la vida como el tejido urbano.

La producción masificada de segundas residencias ha sido posible por la estimulación, movilización y venta de ideas, sentidos e imaginarios (Hiernaux, 2007; 2009), los cuales actúan como representaciones que idealizan determinadas relaciones sociales y espaciales; es decir, operan como verdaderas utopías (Harvey, 2011). Las utopías de las formas espaciales, aunque parecen inmutables, son profundamente dinámicas y revelan no solo las condiciones materiales predominantes en la sociedad (Williams, 2001), sino incluso las posibilidades novedosas y futuras de organización del espacio mediante su proyección a un pasado perdido (Lefebvre, 1980). En ese sentido, una utopía urbana de la anticiudad bastante persistente es la que contrapone el campo, como paraíso, a la ciudad, que sería el infierno. Idealiza al primero como lugar de bondades naturales y armonía, mientras que la última se caracterizaría por su esencia infernal, violenta, peligrosa, alienante y conflictiva (Williams, 2001). Aunque tal utopía rechaza la ciudad, no lo hace respecto de las comodidades que derivan de la vida urbana. Lo que busca es reproducir un pasado rural perdido, pero esta vez con las condiciones sociales imperantes en un determinado momento histórico: el presente. Ejemplos de dicha utopía se pueden encontrar en las elites latinoamericanas, materializados mediante procesos de producción del espacio tales 
como la suburbanización de comienzos del siglo xx (Romero, 2007) y, más recientemente, la masificación en áreas periurbanas de condominios cerrados y ciudades valladas (Hidalgo, 2004).

La masificación de segundas residencias, tanto en contextos de región sin ciudad como en regiones urbanas, se ha dado a partir de distintos ejes. Entre ellos, la confluencia de i) la modernización capitalista (excedentes de capital financiero en búsqueda de valorización y la transformación de ciertas mercancías en activos financieros); ii) de la reestructuración inmobiliaria (concentración y centralización de capital con ampliación de los nichos de reproducción del capital); y iii) también de la globalización y el crecimiento de la industria del turismo, que ha potenciado múltiples formas de actividad turística que se expresan mediante variadas pautas de movilidad. Tales pautas comprenden desde el turismo tradicional (la visita de un lugar por un tiempo determinado con fines diferentes a los de la vida cotidiana común), al turismo residencial (la actividad de habitar una vivienda propia o alquilada por un período de vacaciones), hasta formas de movilidad más definitivas, como las migraciones por estilo de vida o amenidades. Se trata de desplazamientos que agrupan no solo aquellos motivados por necesidades económicas, sociales o políticas (Morales \& Rainier, 2013), sino también a los que obedecen al deseo de disfrutar de paisajes singulares que garanticen el disfrute de una alta calidad de vida (Kondo, Rivera \& Rullman, 2012) y que pueden darse en diferentes edades y condiciones familiares, como por ejemplo las migraciones por retiro.

La producción habitacional para satisfacer la demanda de turistas residenciales, migrantes de retiro o migrantes por amenidades y estilos de vida, se ha centrado, entonces, en la movilización de representaciones espaciales idealizadas en las cuales se evocan significados como el de la armonía, el equilibrio, la tranquilidad y el disfrute de la naturaleza o el paisaje, pero sin perder las comodidades de la simultaneidad y la accesibilidad que definen la vida urbana contemporánea. Dichos productos son así promovidos y comercializados como verdaderas utópolis, que garantizan la recuperación de la armonía con la naturaleza en un entorno que, aunque simula ciertas condiciones de la ciudad, niega generalmente otros de los rasgos de aquella, como la alta densidad, la potencialidad de la multiplicidad de contactos interpersonales y la heterogeneidad social. Por tal motivo, las utópolis se proyectan, i) como condominios verticales u horizontales generalmente de acceso restringido, ii) localizados en lugares valorados socialmente a partir de las cualidades de sitio, iii) con equipamientos privados e infraestructura que pueden hacer prescindible la cercanía a una ciudad, y iv), con un ambiente interior socialmente homogéneo en términos de ingresos: grupos de clase alta o media.

No obstante lo anterior, ese tipo de utópolis, al ser construidas bajo las relaciones sociales de producción que caracterizan al capitalismo contemporáneo, se manifiestan -más allá del marketing inicial- como verdaderas distopías; es decir, como la manifestación de rasgos socioespaciales indeseables que contradicen el presunto carácter armónico e idealizado de las utopías. Un sucinto estado del arte de la producción de segundas residencias en espacios litorales en el ámbito iberoamericano puede resultar ilustrativo de ello. 
En el litoral mediterráneo español, tras una primera fase de emigración de los pobladores locales, hacia la década de los cincuenta se produjo la construcción de infraestructuras turísticas y la llegada de turismo masivo, mientras que en los setenta comenzó el turismo residencial a partir de la edificación de viviendas secundarias, proceso que experimentó un largo boom, hasta el año 2007 (Gaja, 2008; Huete, 2007). Ello fue posible gracias al crédito barato, el aumento del endeudamiento -de los bancos y la ciudadanía-, una elevación de la rentabilidad nominal por la adopción del euro (Gaja, 2008) y, sobre todo, por el aprovechamiento que hicieron los agentes inmobiliarios de normativas de planificación territorial flexibles o incluso la cooptación directa a las administraciones públicas (Delgado, 2008). Espacialmente, la urbanización litoral se inició en los sesenta con la construcción de equipamientos turísticos en muchos municipios costeros, expandiéndose en los ochenta a municipios más alejados (entre 5 y $20 \mathrm{~km}$ del litoral), donde era más barato el suelo. Finalmente, a comienzos de los 2000, se produjo un avance hacia una tercera línea más distante aún, debido a la pérdida de calidad paisajística en las dos líneas anteriores (Mantecón, 2011).

En México, los desarrollos inmobiliarios de segunda residencia en espacios litorales han surgido en ciudades costeras que han ido adaptándose a la recepción de turistas residenciales, y en Centros Integralmente Planeados (CPI) creados por el Fondo Nacional de Fomento al Turismo (Fonatur) a partir de macroproyectos hoteleros dotados de infraestructura urbana (Baños, 2012). El proceso de consolidación turística se dio entre los años cincuenta y setenta, de la mano de la gestión de Fonatur, que perdió impulso en los ochenta con la privatización de la provisión de infraestructura y de la gestión de los espacios turísticos en general. Este país, en conjunto con otros de América Central, como Costa Rica y Panamá, ha recibido oleadas de migración por amenidades ${ }^{4}$ (Janoschka, 2013). Por otro lado, Brasil ha visto un auge del consumo de segundas residencias en espacios de borde costero entre la población nacional, tendencia que en la última década se extendió a migrantes por amenidades de origen extranjero (Silva de Oliveira, 2009); en Uruguay, De Mattos señala un proceso de metropolización litoral en Montevideo, esencialmente mediante condominios turísticos. Y en Colombia, la ciudad de Cartagena, al especializarse en el turismo internacional, ha comenzado a experimentar, también en la última década, un auge de segundas residencias en condominios verticales en el sector de La Boquilla, mediante la renovación patrimonial en Getsemaní (Chaparro \& Santana, 2013) y la construcción de condominios horizontales en el litoral periurbano norte.

Un rasgo que aparece en todos los estudios de caso es que la construcción de segundas residencias suele ir asociada a procesos de especulación inmobiliaria. Estos operan a partir de distintos mecanismos; uno es la existencia de rentas potenciales de monopolio, que en primera instancia no pagan los agentes inmobiliarios a los propietarios originarios, sino que se las apropian, transfiriéndoselas a los consumidores finales mediante un precio de monopolio; otro, la disponibilidad de crédito

Provenientes esencialmente de los Estados Unidos, a diferencia del Mediterráneo español, donde predominan nacionales de Gran Bretaña y Alemania. 
barato. En el caso español, ello generó un tsunami urbanizador (Gaja, 2008), que finalizó con una gran crisis de sobreproducción de vivienda y un crash financiero que sacudió toda la economía nacional. Por otra parte, el boom inmobiliario contemporáneo en los espacios litorales también es producto de la creciente aplicación de las políticas neoliberales a la gestión territorial regional y local. Producto de ello es, por ejemplo, la desregulación de la normativa ambiental para facilitar la urbanización, que ha generado la degradación de los ecosistemas costeros. Así lo reconocen para el caso de Cancún y la Riviera Maya en México, Jiménez y Sosa (2010); para Cantabria, Delgado (2008); y para otros contextos biogeofísicos, diversos autores (Bin \& Brown, 2006; Bin, Poulter, Dumas \& Whitehead, 2011; McNamara, 2013; Romero, Jiménez \& Villoria, 2012). También es secuela de la aplicación de las políticas neoliberales a la gestión territorial regional y local, el aumento de la susceptibilidad a riegos naturales (Babinger, 2012). A ambos mecanismos hay que añadir estrategias de regulación cooptadas por los agentes inmobiliarios (Delgado, 2008), principalmente para garantizar los cambios de zonificación y usos del suelo (Capel, 2013).

Paralelos a estos procesos, suelen presentarse fenómenos de acumulación por desposesión (Harvey, 2013). La presencia de actividades pesqueras o agrícolas ejercidas por comunidades tradicionales de pescadores o agricultores implica rentas del suelo bajas que son potencialmente ampliables a rentas de monopolio, mediante la acción de los agentes inmobiliarios. Ello implica, en el peor de los casos, la expulsión de población local y la llegada de los migrantes por amenidades, cuya consecuencia es un fenómeno que algunos asocian a una especie de gentrificación litoral, descrita en diferentes contextos (Kahn, Vaughn \& Zasloff, 2010; Griffith, 2000; Freeman \& Cheyne, 2008; Collins, 2013; Colburn \& Jepson, 2012; Gil de Lamadrid, 2008). En el mejor de los casos, la población local no es expulsada: los turistas residenciales en estas nuevas localidades no son considerados como algo negativo por la población local, ya que no se percibe que compitan en el mercado de trabajo; incluso residen en núcleos urbanos tradicionales alejados de los macroproyectos (Mantecón, 2011). Sin embargo, la idea promovida por las administraciones locales en el sentido de que ese tipo de urbanización genera más recursos y oportunidades para las comunidades locales, no siempre se concreta. Surgen en ocasiones conflictos de exclusión y segregación, dada la apropiación privada de las playas, los impactos ambientales negativos o la pérdida de los modos de vida tradicionales, lo que plantea retos de gobernanza que no suelen ser superados en contextos caracterizado por la desregulación.

Las viviendas del tipo descrito se proyectan como utópolis. Sin embargo, por diversos factores -como i) su construcción en ecosistemas frágiles, ii) la potencial expulsión o reconversión social y cultural de los grupos locales, iii) la escasa provisión de espacios públicos y la ausencia de la ciudad, iv) la desregulación y el bajo control de dichas externalidades, e incluso v) los conflictos multiescalares debidos a la especulación, el sometimiento del parque de viviendas a los riesgos de devaluación y la creación de crisis inmobiliarias y financieras-, se convierten en distópolis o fragmentos de tejido urbano, que no pueden ser considerados como ciudad en el sentido amplio del término, pues no cuentan con las condiciones necesarias para ello; vale decir, centralidad, simultaneidad y heterogeneidad social. 
La construcción de distópolis de ese tipo contribuye a dar forma a diferentes geografías del proceso de urbanización: puede ser impulsada en pequeños pueblos turísticos, como factor de expansión en ciudades medias (es el caso mexicano) o incluso puede darse en un contexto de metropolización en las grandes urbes (como en el caso de Valencia en España, de Montevideo o de Lima). Esa última modalidad es la que se presenta en la Quinta Región de Valparaíso y cuyo análisis metodológico se esboza a continuación.

\section{Enfoque metodológico: la dialéctica geográfica de la descripción}

Con la muerte de la geografía regional, el método descriptivo fue abandonado (Capel, 1982; Delgado, 2003). Aunque ciertas corrientes del pensamiento geográfico moderno y posmoderno se valen de la descripción -neopositivistas, humanísticos, posestructuralistas, por ejemplo-, al no ser esta el objetivo epistemológico, la reflexión sobre su pertinencia y potencialidad es escasa. Por lo tanto, rescatar elementos del método descriptivo para comprender las geografías de la urbanización contemporánea implica recontextualizar su papel.

Situándonos dentro de una geografía urbana crítica, es posible adoptar el método dialéctico en el que la oposición entre lo abstracto y lo concreto remite a distintas fases del movimiento del pensamiento (Lefebvre, 1970), que se pueden expresar en una secuencia de teoría, descripción teóricamente informada y regreso a la teoría, enriquecida por el mundo de lo concreto $\left(\mathrm{T}-\mathrm{DTI}-\mathrm{T}^{\prime}\right)$. La fase de descripción teóricamente informada (Lefebvre, 1980) implica articular un análisis que penetra en los objetos y en su complejidad -más que en reducirla mediante subdivisiones-, identificando sus propiedades absolutas y relativas, sus características y sus relaciones, mientras que de manera simultánea la síntesis enlaza los elementos en una totalidad, evidenciando su movimiento en conjunto (Lefebvre, 1970).

De la revisión teórica se derivó, entonces, un esquema en el que diferentes macroprocesos - de gran escala social y espacial-, tales como la financiarización, la neoliberalización y la consecuente reestructuración inmobiliaria, impulsan mesoprocesos - de escala espacial y social intermedia-, como la metropolización, al igual que procesos y fenómenos - de expresión más local- como la suburbanización, la densificación de las áreas centrales y la construcción de utópolis / distópolis en espacios costeros (figura 1). Los procesos y fenómenos han sido expresados como variables analizadas a partir de diversas fuentes (censos, publicaciones estadísticas, mapas, imágenes satelitales y trabajo de campo) para diferentes momentos entre 1992 y 2012. De ese ejercicio se pasó a la identificación de las variaciones espaciotemporales de cada variable-proceso mediante un análisis cartográfico y estadístico, que es articulado mediante una narrativa sintética en la que se reconstruyen las fases, relaciones e implicaciones del proceso de producción de distópolis en el litoral central de Chile. 
FIGURA 1 | Macroprocesos, mesoprocesos, procesos, fenómenos y relaciones

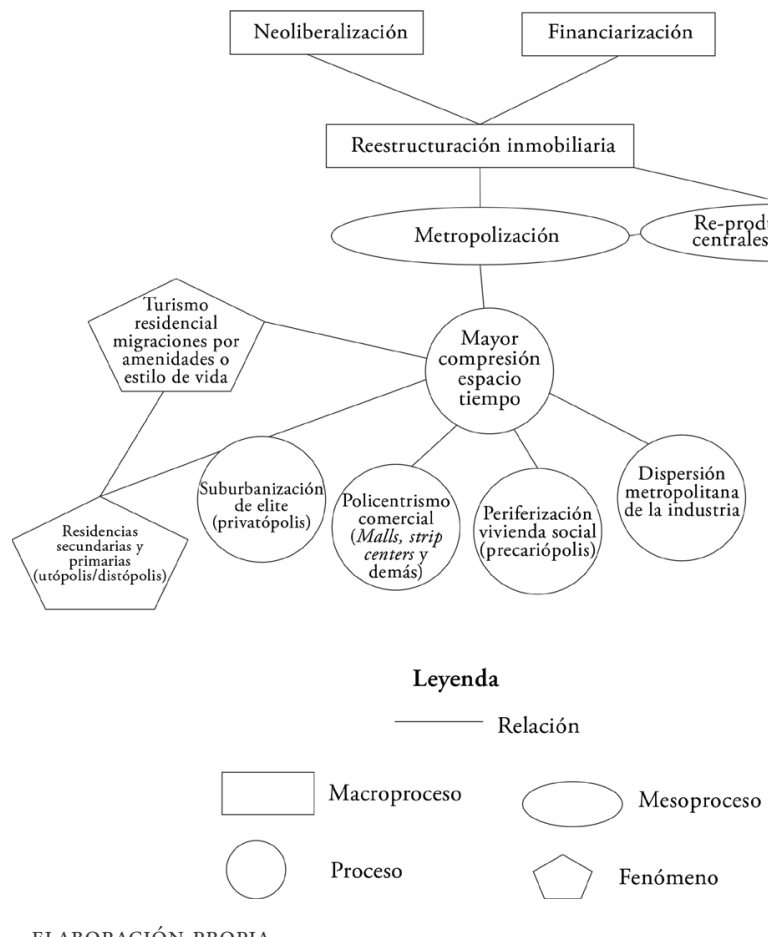

FUENTE ELABORACIÓN PROPIA

\section{Una introducción al proceso de metropolización en la macrozona urbana central de Chile}

La metropolización surgió de manera incipiente en la década de los cuarenta en Santiago de Chile (Hidalgo, Arenas et al., 2014). Sin embargo, desde finales de la década de los setenta y comienzos de los ochenta, se gestaron los mecanismos para un proceso intenso de valorización del capital financiero e inmobiliario en el país. Se trató de reformas liberalizadoras del mercado del suelo periurbano -la ley de predios rústicos, DFL 3.516 de 1980-, paralelas a las reformas del mercado de trabajo, de la seguridad social y de la provisión de vivienda social (Hidalgo, Borsdorf \& Sánchez, 2005; Cattaneo, 2011). La liberalización del mercado del suelo periurbano constituye una política que se ha extendido en el tiempo, incluso mediante la lógica de producción y gestión público-privada de una moderna red de autopistas metropolitanas (Hidalgo, Volker \& Ramírez, 2014). Esta red ha sido el catalizador de un acelerado proceso de conformación de una región urbana (De Mattos, 2011) en la que se traslapan de manera coalescente tanto el Área Metropolitana de Santiago (AMs), como el Área Metropolitana de Valparaíso (AMV), aglomeraciones desde las cuales se van involucrando nuevas comunas como espacios periurbanos, hecho que Hidalgo, Arenas et al. (2014) denominan como la nueva macrozona urbana central de Chile. 
El crecimiento demográfico, tanto en la Región Metropolitana como en la de Valparaíso, revela una pérdida del dinamismo de las comunas centrales de las aglomeraciones principales de Santiago y Valparaíso. En ambos casos, estas comunas presentan porcentajes de crecimiento negativos que van desde $-1,5$ a $-0,05$ en el período intercensal 1992-2002. Las comunas más distantes a las aglomeraciones centrales crecen a niveles de entre $0 \%$ y $2 \%$, mientras que las que reportan un mayor dinamismo (más de $2 \%$ anual) se concentran en: i) los bordes periurbanos de Santiago (Maipo, Maipú, Pudahuel, Lampa, Colina, Lo Barnechea, Puente Alto, Pirque, Paine, Buin, San Bernardo, Isla de Maipo, Talagante, El Monte, Peñaflor, Padre Hurtado); ii) el eje de la autopista Santiago-Valparaíso; iii) al nororiente del Valparaíso en Quilpué y Villa Alemana; y iv) en las comunas del litoral tanto en el sur como en el norte de Valparaíso y Viña del Mar, comuna, esta última, que presenta un crecimiento muy leve, de solo $0,05 \%$ anual.

\section{FIGURA 2 | Porcentaje anual de crecimiento demográfico entre 1992 y 2002}

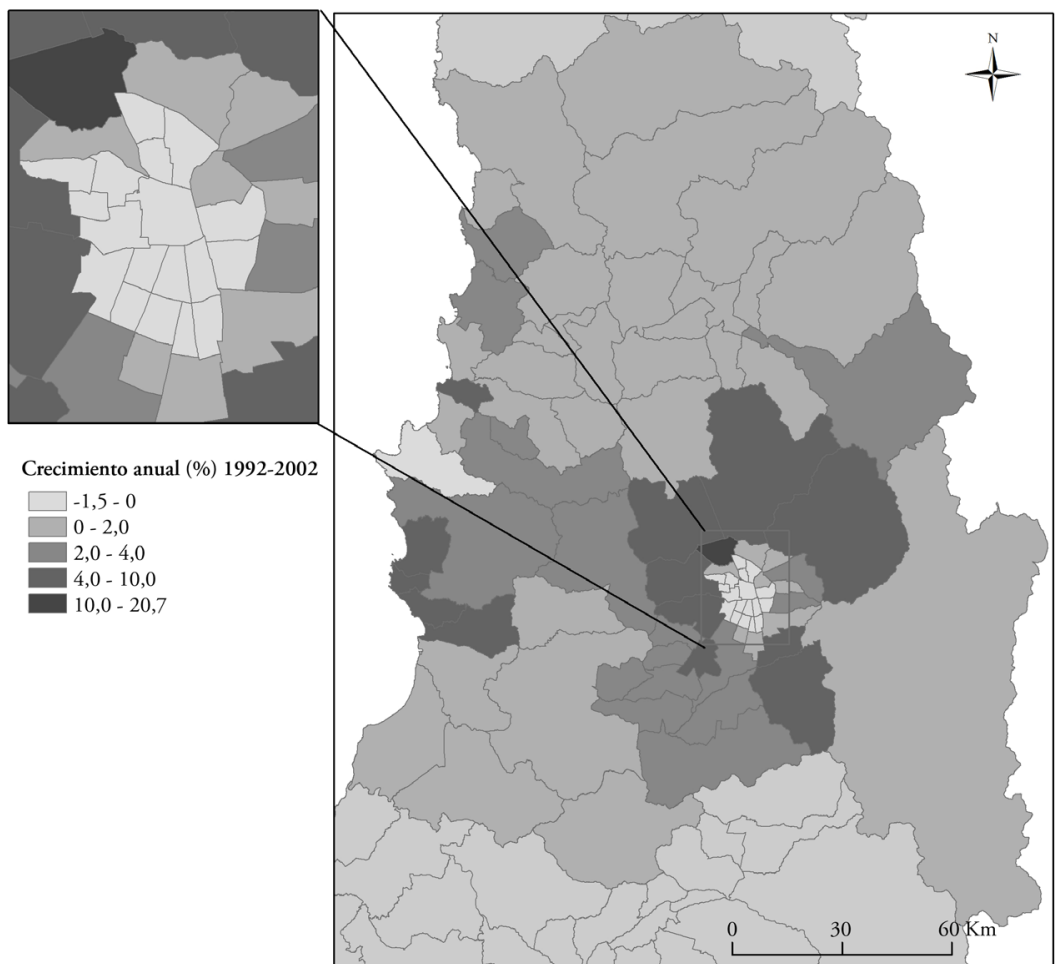

FUENTE ELABORACIÓN PROPIA CON DATOS DE LOS CENSOS DE POBLACIÓN Y VIVIENDA (INSTITUTO NACIONAL DE ESTADÍSTICAS [INE], I992; 2002)

De las mencionadas transformaciones demográficas, se puede inferir que ha surgido una estructura funcional de carácter policéntrico en la macrozona urbana del centro de Chile: shoppings centers, parques industriales, precariópolis estatales y privatópolis inmobiliarias (Hidalgo et al., 2005; Hidalgo et al., 2008) han sido producidos por 
los agentes inmobiliarios en comunas periurbanas cada vez más distantes. Ello ha sido posible a partir de la aniquilación del espacio por el tiempo, es decir, de la construcción de las autopistas metropolitanas y una mejora sustancial en la densidad de las vías pavimentadas tanto en la Región Metropolitana como en la Región de Valparaíso (cuadro 1), que ha permitido reducir los tiempos de desplazamiento cotidiano. La figura 3 indica que los circuitos con mayor flujo vehicular en la red vial son Santiago-Valparaíso y Santiago-San Antonio, debido a relaciones funcionales entre los puertos y el gran mercado del país. Hay, además, circuitos locales en el surponiente y norponiente del AMs, así como otros en comunas litorales del norte y sur de la Región de Valparaíso, lo que indica la articulación funcional de esas áreas.

CUADro 1 | Longitud de vías pavimentadas en las regiones Metropolitana y de Valparaíso

\begin{tabular}{|c|c|c|c|c|c|}
\hline \multirow{2}{*}{ ÁREA } & AÑo & LONGITUD (M) & $\begin{array}{c}\text { PAVIMENTADo } \\
(\%)\end{array}$ & $\begin{array}{c}\text { DENSIDAD } \\
(\mathbf{M} / \mathbf{K M 2})\end{array}$ & $\begin{array}{c}\text { VARIACIÓN } \\
(\%)\end{array}$ \\
\hline \multirow{2}{*}{ Región de Valparaíso } & 2001 & $1.285 .761,50$ & 41,2 & 79,6 & \multirow{2}{*}{208,2} \\
\cline { 2 - 5 } & 2012 & $2.677 .386,10$ & 83,1 & 165,8 & \\
\hline \multirow{2}{*}{ Región Metropolitana } & 2001 & $1.573 .830,80$ & 47,7 & 93,2 & \multirow{2}{*}{170,2} \\
\cline { 2 - 5 } & 2012 & $2.559 .751,10$ & 78,1 & 158,6 & \\
\hline
\end{tabular}

FUENTE ELABORACión PROPIA CON DATOS DEL MiNisterio DE ObRAS PÚbliCAS (MOP) (2OI4)

FIGURA 3 | Flujo vial entre comunas de la Región de Valparaíso y Metropolitana en 2010
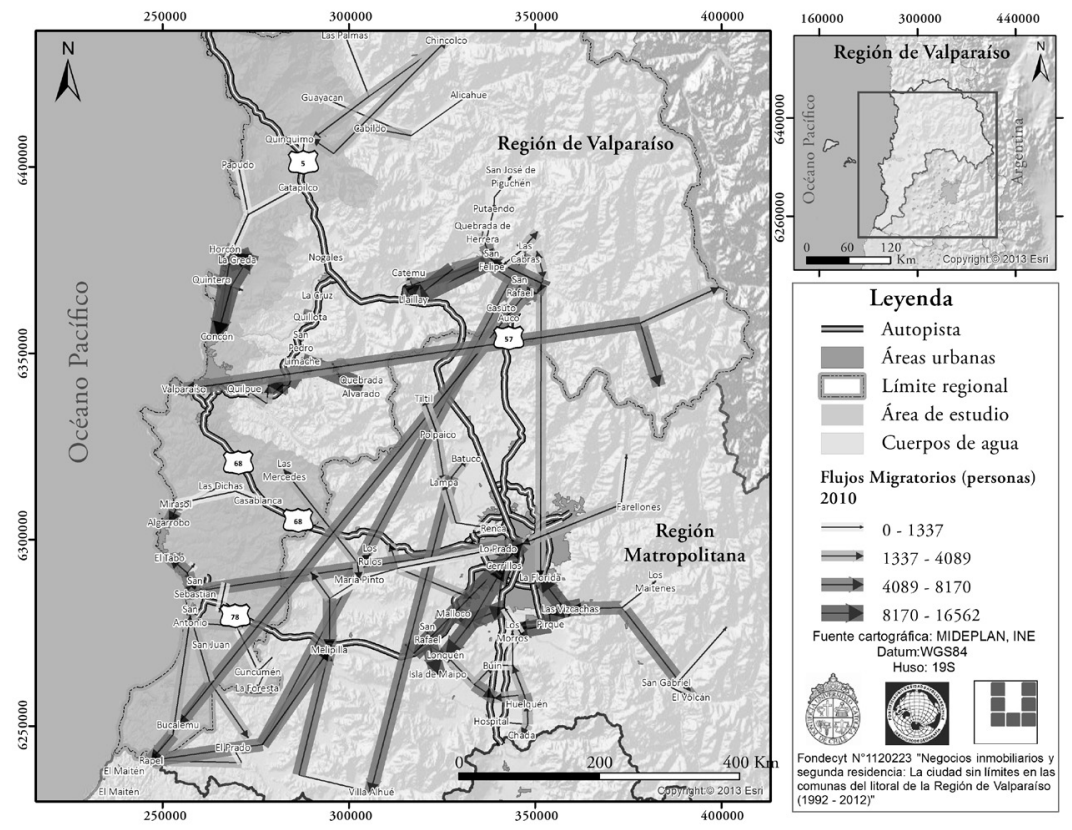

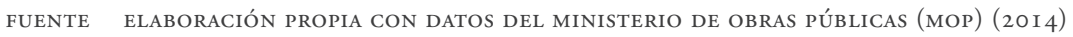


Las comunas litorales de la Quinta Región se han constituido en importantes núcleos metropolitanos con altas tasas de crecimiento demográfico. La integración del espacio metropolitano, además de favorecer los nexos funcionales de vecindad con la ciudad de Valparaíso, ha permitido una mayor articulación entre el espacio del borde costero - con las amenidades del medio físico derivadas de su condición de sitio- y el AMs, abriendo así un nuevo frente de urbanización con grandes perspectivas para la valorización de capitales en el sector inmobiliario.

\section{De las utópolis modernas a la posmodernas en el litoral central de Chile}

La singularidad de la urbanización y de los procesos de metropolización contemporáneos en los espacios costeros surge de las condiciones de sitio y situación que los caracterizan. Tales conceptos, que han sido la base del análisis geográfico, dan cuenta de las características de los valores de uso que son puestos en circulación por los agentes inmobiliarios. Por un lado, el sitio puede ser conceptualizado como un valor de uso ligado tanto a la capacidad portante del medio físico para el emplazamiento de un artefacto urbano (Gray, 1987), como a marcas del medio social inspiradas en el prestigio y la valoración cultural. Por otro, el concepto de situación expresa la relación del elemento urbano con los demás elementos presentes, sean componentes del medio físico -condiciones geomorfológicas, climáticas, biogeográficas (George, 1969; Dollfus, 1978)-, pero también objetos producidos socialmente. Por ello, el valor de uso de las diversas mercancías inmobiliarias cuenta con atributos de sitio y situación -de espacio absoluto y relativo- fundamentales (Harvey, 1990), que implican la valoración social de las características de la primera y de la segunda naturaleza.

La región de Valparaíso cuenta con condiciones de sitio singulares: es una de las regiones chilenas -junto a la de Coquimbo- con una gran extensión de playas (Castro \& Hidalgo, 2002) ubicadas en pequeńas llanuras de abrasión, bordeadas por acantilados marinos y relieves tabulares de poca inclinación, que van de 20 a 200 metros. En ellas hay campos de dunas antiguos o activos -Concón, Tunquén o Algarrobo-, gozan de un clima mediterráneo templado (Morales \& Allesch, 1996) y aguas frías por la cercanía de la corriente de Humboldt. Esas condiciones permitieron un temprano y espontáneo desarrollo de balnearios en la ciudad de Valparaíso, que tras la expansión del eje ferroviario en el siglo XIX se relocalizaron en zonas aledańas a las áreas industriales de Viña del Mar. Los balnearios en ese sector pasaron a ser un elemento clave para el boom inmobiliario, que convertirían a Viña en una "ciudad jardín” (Cáceres \& Sabatini, 2003). La construcción del ferrocarril Valparaíso-Santiago, además de impulsar la suburbanización litoral en Viña del Mar, potenciaría el turismo con la construcción de segundas residencias para las elites santiaguinas en Algarrobo y Santo Domingo, en conjuntos modelados a partir de la ciudad radial, como lo ejemplifica el balneario de Las Cruces (Castro \& Hidalgo, 2002). La valoración del paisaje costero, la mejora en la accesibilidad y la edificación de casas de veraneo, incluso bajo trazados de ciudad jardín o radial, propiciaron la construcción de utópolis modernas para la burguesía local y santiaguina. 
La construcción de las autopistas concesionadas a partir de comienzos del siglo Xxi ha producido una nueva fase de compresión espacio-temporal metropolitana, abriendo nuevos frentes para la valorización inmobiliaria en el litoral de la región de Valparaíso. Se trata de un proceso iniciado en la década de los noventa, en una secuencia que comienza por la instalación de balnearios en las tradicionales caletas de pescadores y que se completa con la construcción de segundas residencias (Andrade \& Hidalgo, 1996; Sánchez \& Cárdenas, 2000; Valdebenito, 2014). Estas viviendas suelen ser promocionadas mediante representaciones que exaltan la vista al mar, la playa y una serie de infraestructuras para el ocio, como piscinas y áreas verdes privadas, que simulan artificialmente la naturaleza (figura 4). Sin embargo, difieren de las utópolis modernas en que son construidas bajo la lógica del urbanismo posmoderno; es decir, como condominios cerrados con pretensión de autosuficiencia y que, aunque reproducen el tejido urbano, no están asociadas a la ciudad.

\section{FIgURA 4 Promoción inmobiliaria de utópolis en comunas del litoral central chileno}

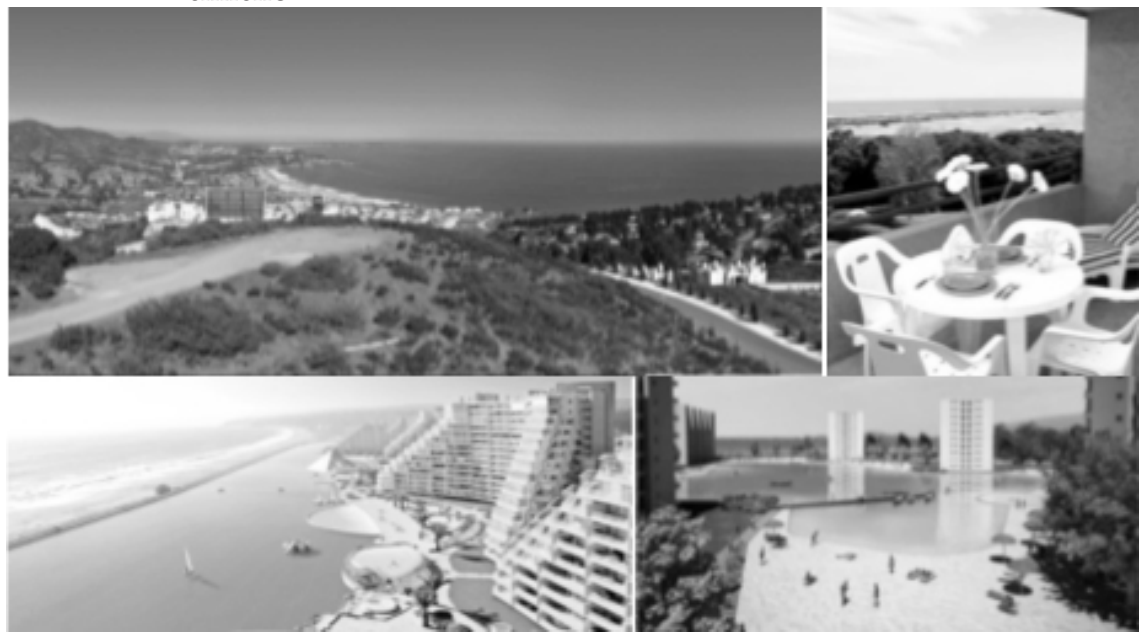

FUENTE PÁGINAS WEB DE LOS PROYECTOS, EN ORDEN DE IZQUIERDA A DERECHA Y DE ARRIBA A ABAJO: I) DPTOS. ALTOS COSTA CACHAGUA EN ZAPALLAR; 2) EL SOLAR DE MANTAGUA EN QUINTERO; 3) SAN ALFONSO DEL MAR EN ALGARROBO Y 4) PAPUDO LAGUNA EN PAPUdO

\section{Produciendo más utópolis...}

\section{Transformaciones demográficas}

La construcción de esas utópolis posmodernas en el litoral de la Quinta Región ha ido a la par de un proceso de transformación demográfica. A pesar del descenso promedio del porcentaje de crecimiento anual en el área de estudio para el último período intercensal, las comunas de esa área presentan niveles entre moderados y muy altos de crecimiento, tanto entre 1992 y 2002 como entre 2002 y 2012 (cuadro 2): el dinamismo demográfico para el primer período estuvo repartido de manera desigual 
entre unas pocas comunas al norte de Valparaíso (Puchuncaví, Zapallar y Quintero) y varias del sur (El Tabo, El Quisco, Algarrobo, Cartagena), mientras que comunas del norte crecieron de manera moderada, con los porcentajes más bajos en Viña del Mar y Valparaíso, incluso con niveles negativos. En el período intercensal 20022012, el dinamismo demográfico, además de ser menor, se concentró en comunas al norte de Valparaíso (Quintero y Puchuncaví), así como en otras del sur (Algarrobo, Santo Domingo y El Quisco). Niveles de crecimiento moderado y bajo se registraron en las demás comunas, incluyendo Valparaíso, San Antonio y Viña del Mar.

CUADro 2 | Grupos de comunas por porcentaje de crecimiento anual, 19922002 y $2002-2012$

\begin{tabular}{|c|c|c|c|c|c|}
\hline COMUNA & $\begin{array}{c}\text { PORCENTAJE DE } \\
\text { CRECIMIENTO } \\
\text { ANUAL I } 992-2002\end{array}$ & $\begin{array}{c}\text { GRUPO } \\
92-02\end{array}$ & COMUNA & $\begin{array}{c}\text { PORCENTAJE DE } \\
\text { CRECIMIENTO } \\
\text { ANUAL 2OO2-2OI } 2\end{array}$ & $\begin{array}{c}\text { GRUPO } \\
\text { O2-I } 2\end{array}$ \\
\hline Concón & $7,5^{*}$ & & Quintero & 3,1 & \\
\hline El Tabo & 6,2 & & Algarrobo & 2,2 & \\
\hline El Quisco & 5,9 & & Santo Domingo & 2,2 & \\
\hline Algarrobo & 4,7 & & El Quisco & 2,1 & \\
\hline Cartagena & 4,5 & & Puchuncaví & 2,1 & \\
\hline Casablanca & 3,2 & & Concón & 1,9 & \\
\hline Puchuncaví & 2,8 & & Viña del Mar & 1,5 & \\
\hline Zapallar & 2,7 & & Casablanca & 1,5 & \\
\hline Quintero & 2,3 & & El Tabo & 1,4 & \\
\hline Santo Domingo & 2,0 & & Zapallar & 1,1 & \\
\hline Papudo & 1,9 & & Papudo & 1,0 & \\
\hline La Ligua & 1,7 & & Cartagena & 0,7 & \\
\hline San Antonio & 1,1 & & Valparaíso & 0,7 & \\
\hline Viña del Mar & 0,1 & & La Ligua & 0,4 & \\
\hline Valparaíso & $-9,0$ & & San Antonio & 0,1 & \\
\hline
\end{tabular}

FUENTE ELABORACIÓN PROPIA CON DATOS DEL CENSO DE POBLACIÓN Y VIVIENDA (INSTITUTO NACIONAL DE ESTADÍSTICAS [INE], I992; 2002; 20I2)

NOTA EN COLOR BLANCO, COMUNAS DE CRECIMIENTO DEMOGRÁFICO ACELERADO; EN GRIS, CON CRECIMIENTO MODERADO; Y EN NEGRO, CON TASAS NEGATIVAS.

* la comuna de concón fue creada como unidad político-administrativa en i995, por lo QUE EL DATO SOBREESTIMA EL CRECIMIENTO.

El descenso del crecimiento demográfico ha ido acompañado de una redistribución importante de los flujos migratorios de llegada a las comunas del borde costero. Se destaca el aumento de la población inmigrante en comunas del eje norte - de Viña del Mar a Papudo- y la consolidación de un núcleo dinámico al sur, en las comunas localizadas entre San Antonio y Valparaíso, durante el último período de medición entre 1997 y 2002 (figura 5a). Aunque para el ańo 2012 no se cuenta 
con información censal sobre migraciones, los resultados de la encuesta Casen (Ministerio de Desarrollo Social, 2011) demuestran que la migración interna, interregional e intercomunal, ocurrida entre 2006 y 2011, ahora se concentra en dos grupos de comunas 5 : uno al norte, integrado por Papudo, Zapallar y Puchuncaví; y otro al sur compuesto por Algarrobo, El Tabo, El Quisco, Cartagena y Casablanca.

Figura 5a y 5b| Tasas de migración (inmigrantes por 1000 habitantes) 19871992 y 1997-2002; proporción de inmigrantes de 65 años y más en 1987-1992 y 1997-2002
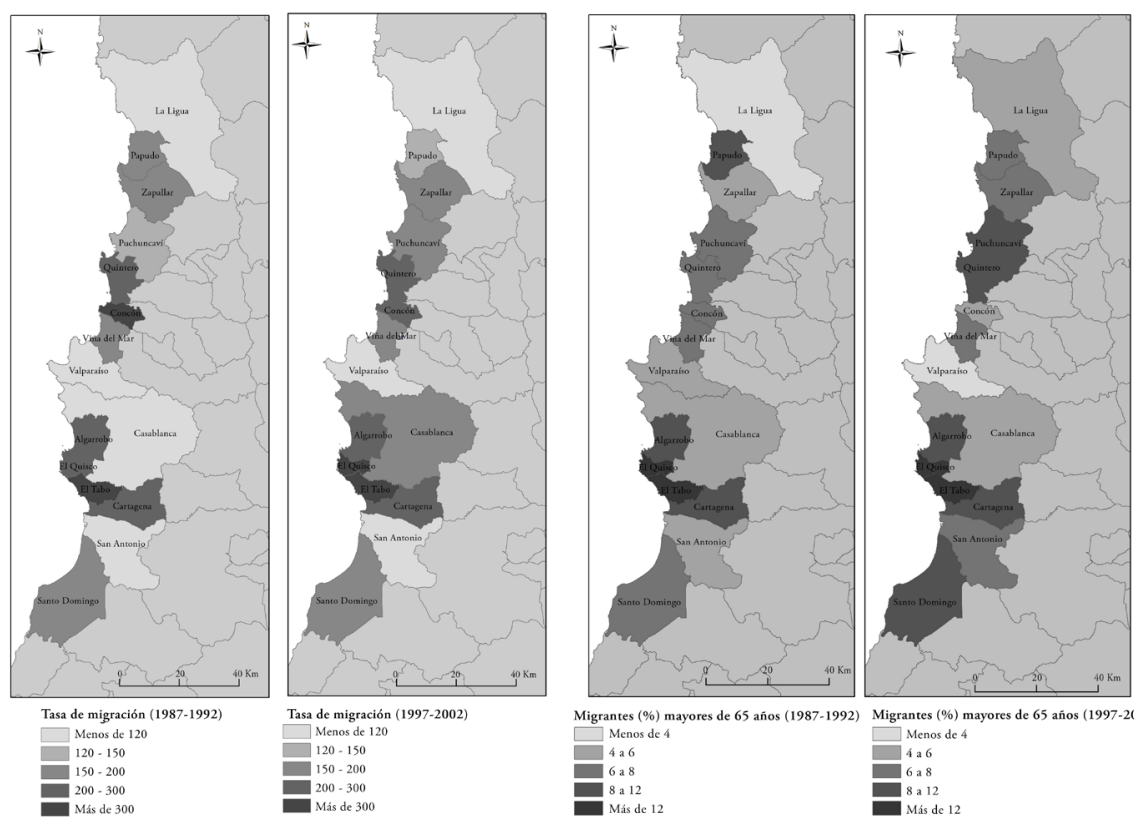

FUENTE ELABORACIÓN PROPIA CON DATOS DEL CENSO DE POBLACIÓN Y VIVIENDA (INSTITUTO NACIONAL DE ESTADÍSTICAS [INE], I 992; 2002)

Dentro de esos flujos migratorios, la población de más de 65 años ha ido incrementando su participación respecto al resto de los migrantes (figura 5b), lo que evidencia la existencia de migraciones de retiro esencialmente en comunas como Puchuncaví, Quintero, Zapallar y Santo Domingo. No obstante, aunque aumentó el promedio de este tipo de migración -de 7,7\% a 8,6\%-, todavía es un fenómeno incipiente. Y en cuanto al porcentaje de migrantes extranjeros, a diferencia de otros flujos migratorios que han dinamizado el turismo residencial en espacios litorales, en los períodos 1987-1992 y 1992-2002 en el área de estudio oscila tan solo entre 4\% y 5\%.

5 La tasa de inmigración calculada con los datos de la encuesta Casen es baja en términos absolutos, por derivar de una muestra. No obstante, arroja resultados interesantes, de mayor a menor, en: Papudo, Puchuncaví, Algarrobo, El Tabo, Cartagena, Zapallar, Casablanca, El Quisco, Valparaíso, La Ligua, Viña del Mar, Concón, Quintero, San Antonio y Santo Domingo. 
Dinámicas inmobiliarias: del boom de las segundas residencias al boom de la residencia principal

En la mayoría de las comunas del litoral, el crecimiento demográfico impulsado por la inmigración fue a la par de un intenso proceso de construcción de viviendas entre 1992 y 2002 (figura 6a), que varió en más del 25\% para todas las comunas al norte y al sur de la ciudad de Valparaíso, concentrándose espacialmente en comunas como Puchuncaví, Concón y Algarrobo, y en menor medida en Papudo, Casablanca y Santo Domingo. Posteriormente, entre 2002 y 2011, se aceleró aún más el proceso de ampliación del parque de viviendas en toda el área de estudio; surgieron dos áreas que presentaron variaciones superiores al 70\%: de Quintero a Zapallar en el eje norte, y desde Algarrobo a El Tabo en el eje sur (figura 6a). Para ambos períodos es posible identificar que la variación del parque residencial es menor en las ciudades conurbadas más grandes de la región -Valparaíso, Viña del Mar y San Antonio-, mientras que sufrió cierta desaceleración en Concón.

FIGURA 6a y 6b | Variación porcentual del stock de viviendas entre 1992 y 2002 y 2002 y 2011. Variación de viviendas desocupadas entre 1992 y 2002 y 2002 y 2011

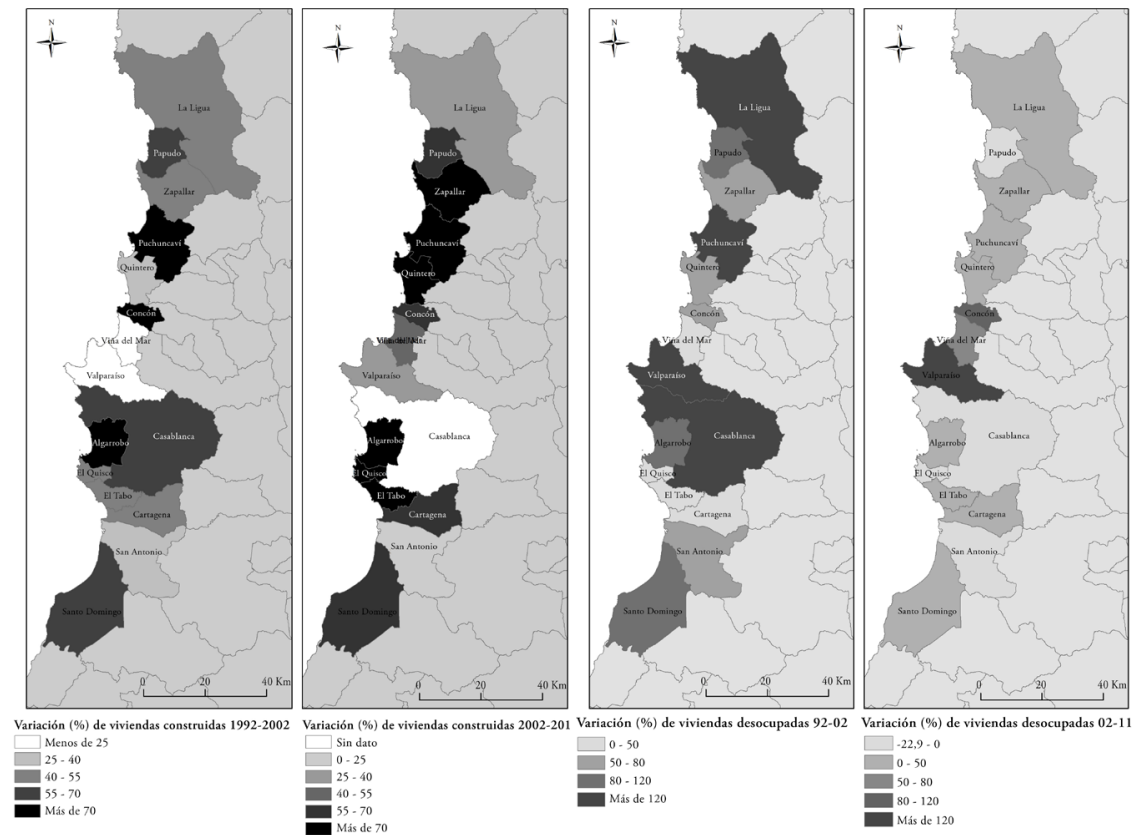

FUENTE ELABORACIÓN PROPIA CON DATOS DEL CENSO DE POBLACIÓN Y VIVIENDA Y DEL PRECENSO 2O I (INSTITUTO NACIONAL DE ESTADÍSTICAS [INE], I 992; 2002; 20I I)

La variación del stock de viviendas entre 1992 y 2002 fue a la par de un alto incremento porcentual de las viviendas desocupadas (figura 6b), por lo que puede colegirse que en ese período se produjo un auge en la construcción de segundas 
residencias. Sin embargo, el intenso incremento del parque de viviendas entre 2002 y 2011 se relaciona con una significativa reducción de las viviendas desocupadas (figura, 6b) revirtiéndose el fenómeno de la segunda residencia.

En 1992, comunas como Algarrobo, El Quisco, El Tabo, Cartagena y Santo Domingo en el eje sur, y Papudo y Zapallar en el eje norte, se daba un predominio de viviendas desocupadas, situación que se intensificó en esas comunas y en Puchuncaví en 2002, para cambiar drásticamente en 2011, año en el que las residencias desocupadas no superaron el 50\% en ninguna comuna del área de estudio (figura 7). Lo anterior confirma que a partir de una primera época de construcción de segundas residencias hasta 2002, se ha pasado, tras una mayor compresión del espacio-tiempo metropolitano, a una fase de metropolización litoral en la que el auge inmobiliario se intensificó, pero esta vez orientado a la construcción de viviendas principales.

FIGURA 7 | Porcentaje de viviendas ocupadas y desocupadas en 1992, 2002 y 2011

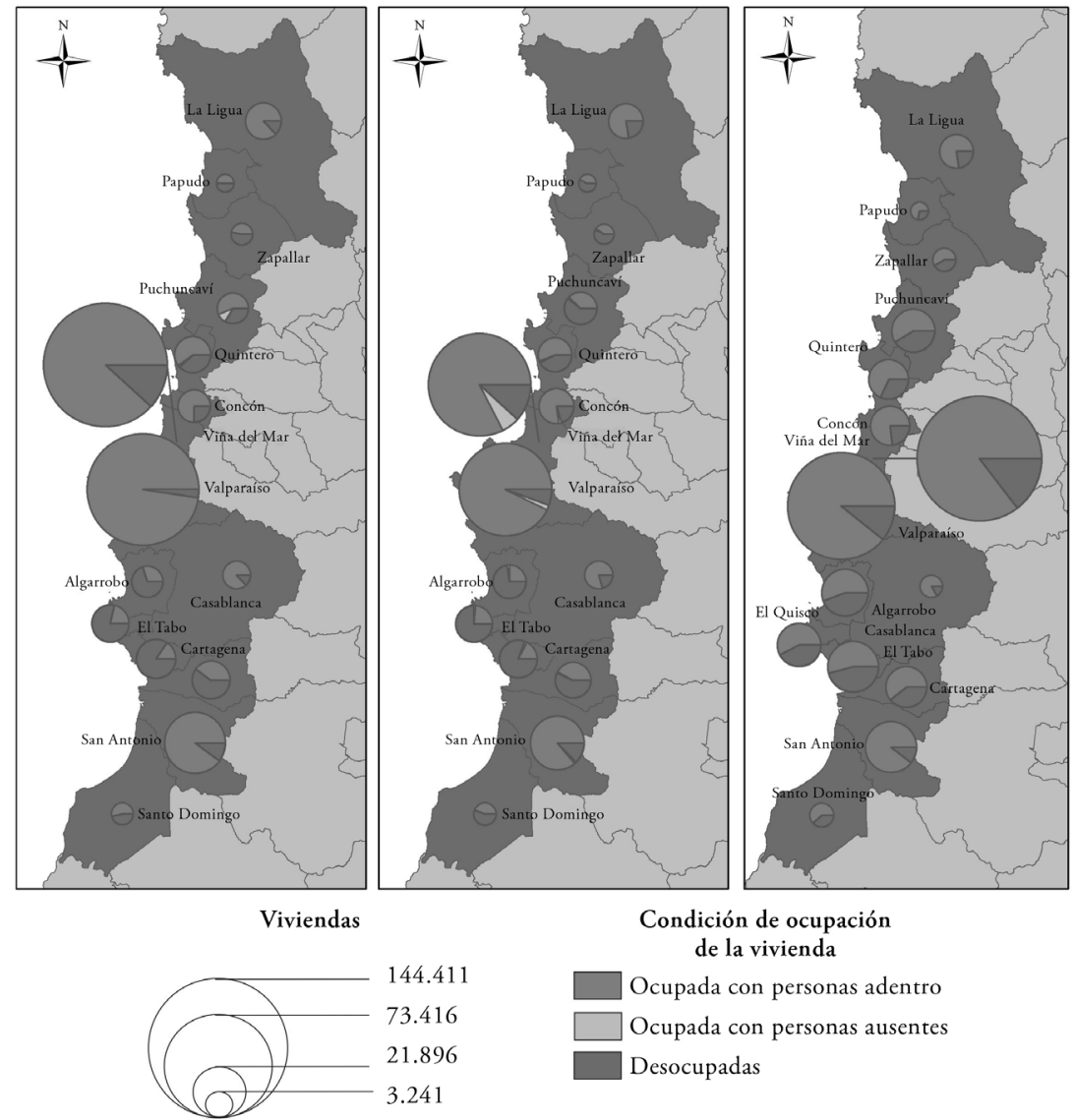

FUENTE ELABORACIÓN PROPIA CON DATOS DEL CENSO DE POBLACIÓN Y VIVIENDA Y DEL PRECENSO 2OI I (INSTITUTO NACIONAL DE ESTADíSTICAS [INE], I992; 2002; 20I I) 
Figura 8a y 8b | Proyectos inmobiliarios construidos entre 1992 y 2012 y variación porcentual del área urbana (2003-2010). Precio promedio de las transacciones de compra de vivienda en UF entre 2004-2010 y volumen promedio de las transacciones en pesos para el mismo período

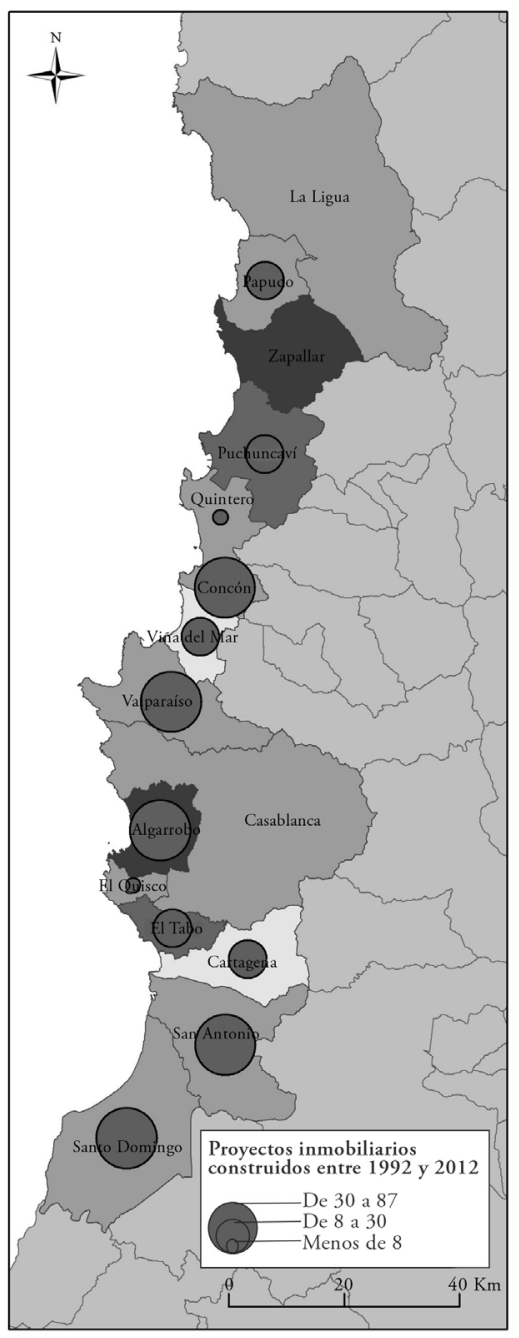

Variación (\%) del área urbana entre 2003 y 2011

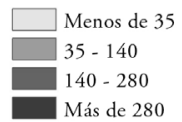

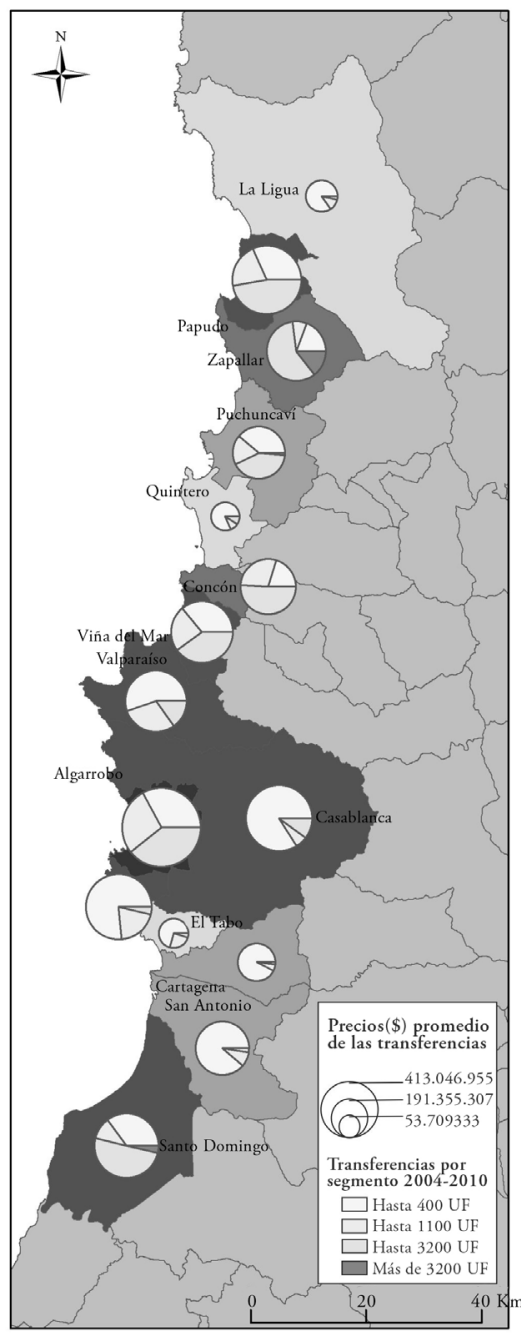

Transferencias (UF) por segmentos (2004-2010)

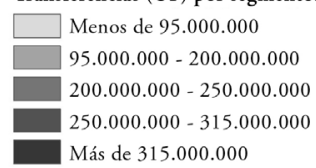

FUENTE ELABORACIÓN PROPIA CON DATOS DE PERMISOS DE EDIFICACIÓN, MINISTERIO DE VIVIENDA Y URBANISMO (MINVU) Y CONSERVADORES DE BIENES RAÍCES (CBR) COMUNALES, 2004-20IO 
Los proyectos inmobiliarios residenciales construidos entre 1992 y 2012 no se correlacionan directamente con el tamaño poblacional de cada comuna, sino con la variación positiva de las manchas urbanas (figura 8a). La mayoría de las comunas presentaron entre 8 y 87 condominios $^{6}$; e incluso en algunas de ellas, como Concón o Puchuncaví, los macroproyectos inmobiliarios representaron entre un $11 \%$ y un $52 \%$ del total. La transferencia de viviendas por segmentos de precio en Unidades de Fomento (UF) ${ }^{7}$ entre 2003 y 2010 demuestra que ha surgido una clara especialización del mercado de la vivienda en el área de estudio: por un lado, comunas como Papudo, Zapallar, Puchuncaví, Concón, Viña del Mar y Santo Domingo presentan una mayor proporción de transacciones en la categoría de 1.100 uf hasta más de 3.200 UF, mientras que en otras ubicadas al sur predominan transacciones de menos de $1.100 \mathrm{UF}$, aunque el volumen de las transferencias es mayor en las últimas (figura 8b).

FIGURA 9 | Valor promedio (UF) de los proyectos inmobiliarios ofertados en 2012

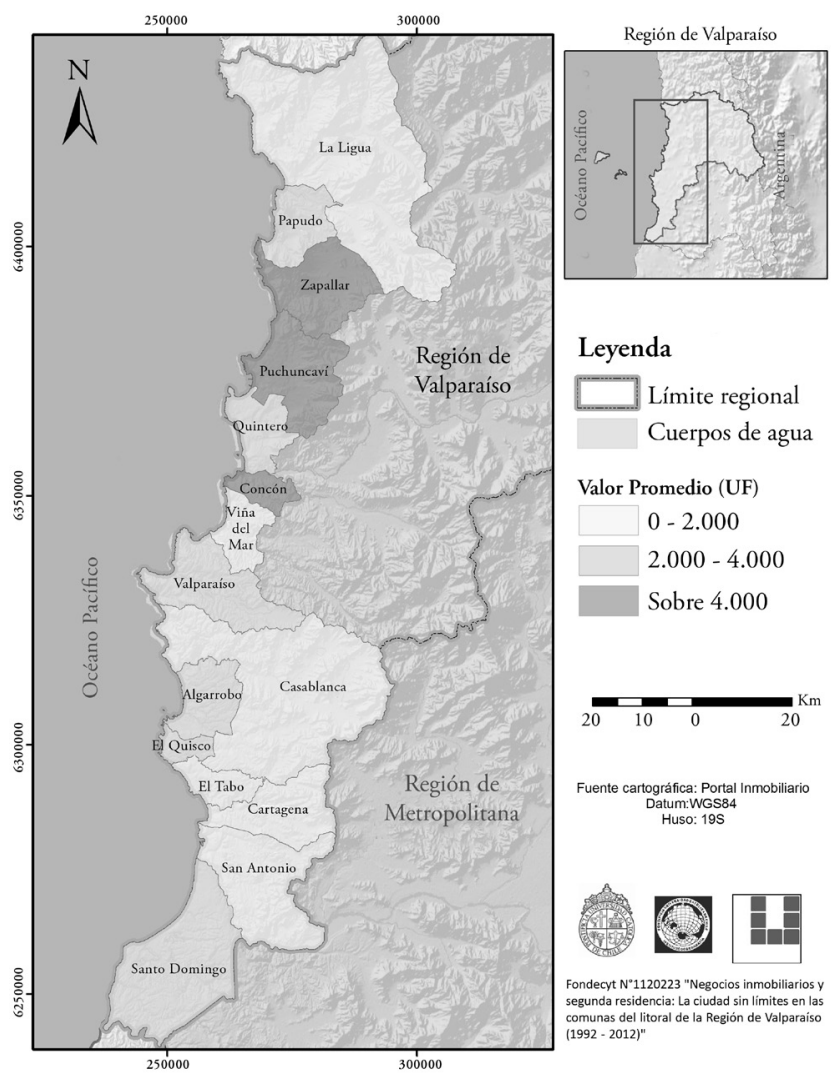

FUENTE ELABORACIÓN PROPIA CON DATOS DEL PORTAL INMOBILIARIO HTTP://WWW. PORTALINMOBILIARIO.COM/

6 Proyectos que están conformados por 10 o más viviendas.

7 La Unidad de Fomento (UF) es una medida que varía en función de la inflación. Equivale en 2015 a aproximadamente 37,5 dólares estadounidenses. 
La segmentación del mercado de la vivienda en el área de estudio ha contribuido, entonces, a delinear una geografía de la especulación inmobiliaria centrada en un eje norte casi continuo, que se extiende desde Concón -que interrumpe parcialmente la comuna de Quintero-, pasando por Puchuncaví y Zapallar, para finalizar en Papudo y en núcleos al sur, como Santo Domingo, Algarrobo y El Quisco, mientras que en el centro destaca la aglomeración Valparaíso-Viña del Mar (figura 9). El boom inmobiliario de los noventa ha producido una saturación residencial de los sectores litorales en suburbios tradicionales como Viña del Mar y Concón, así como una intensificación en la construcción de condominios de litoral en comunas de larga tradición turística, como Santo Domingo, Cartagena y Algarrobo, mientras que ha abierto nuevas fronteras en comunas del norte, como Puchuncaví, Papudo y Zapallar, o en el sur en El Tabo y El Quisco. El surgimiento de esa nueva geografía metropolitana en el litoral va a la par de potenciales conflictos sociales y ambientales.

\section{¿Construyendo distópolis?}

La promoción de utópolis en el litoral de la Quinta Región ha propiciado una reestructuración de la geografía social de los espacios del borde costero. El Índice de Desarrollo Social (IDS), indicador compuesto de variables agrupadas en tres categorías -bienes suntuarios, años de estudio y calidad de la vivienda-, aumentó en toda el área de estudio entre 1992 y 2002 (figura 10). Sin embargo, es en los distritos censales ubicados en el litoral donde se registraron los mayores incrementos del índice, revelando que la inmigración a esas zonas se compone de población con niveles de ingresos altos y medios, distribuida en los ya mencionados ejes del norte, de Viña del Mar a Papudo, y del eje sur, desde Algarrobo hasta Santo Domingo.

Lo anterior revela la existencia de un proceso de elitización que puede plantear potenciales conflictos. Por un lado, el éxodo actual de las elites locales fuera de la ciudad de Valparaíso ha implicado el abandono de sectores residenciales en esa urbe (Hidalgo, Borsdorf \& San Martín, 2013; Borsdorf \& Hidalgo, 2013), propiciando una devaluación del parque de viviendas local. Por otro, la llegada de clases altas y media alta a comunas del borde litoral en el eje norte o sur podría haber ocasionado expulsión de población local. Otros impactos de la construcción de utópolis tienen que ver con potenciales disputas por el acceso a las playas, la presión inmobiliaria en los asentamientos tradicionales o la especulación en el precio de las viviendas, y encarecimiento del nivel de vida en la zona.

Aunque el marketing inmobiliario generalmente se basa en imágenes que exaltan lo que hay al interior de los condominios, los espacios de contacto entre los proyectos y las zonas aledañas no son visibles. Prevalecen como modalidad morfológica de las utópolis los condominios cerrados, sean horizontales (en zonas de terrazas marinas más alejadas), verticales (en la base de los acantilados, las planicies costeras o incluso en el primer nivel de terrazas marinas) o mixtos (generalmente macroproyectos con más de 50 viviendas). Muchos de los proyectos construidos incluyen servicios privados -salas multiuso ( $40,9 \%$ de los casos), piscinas $(38,6 \%)$, gimnasios $(36,3 \%)$ parques de juegos $(31,8 \%)$ y lavanderías $(31,8 \%)$-, ofertados e incluso gestionados por las mismas empresas inmobiliarias (Hidalgo \& Janoschka, 2014). Por lo tanto, 
la promoción contemporánea de utópolis en el litoral se caracteriza por la propagación de tejido urbano sin ciudad: sin espacios públicos ni equipamientos urbanos accesibles a toda la población.

FIGURA 10 | Índice de Desarrollo Social en el área de estudio en 1992 y 2002

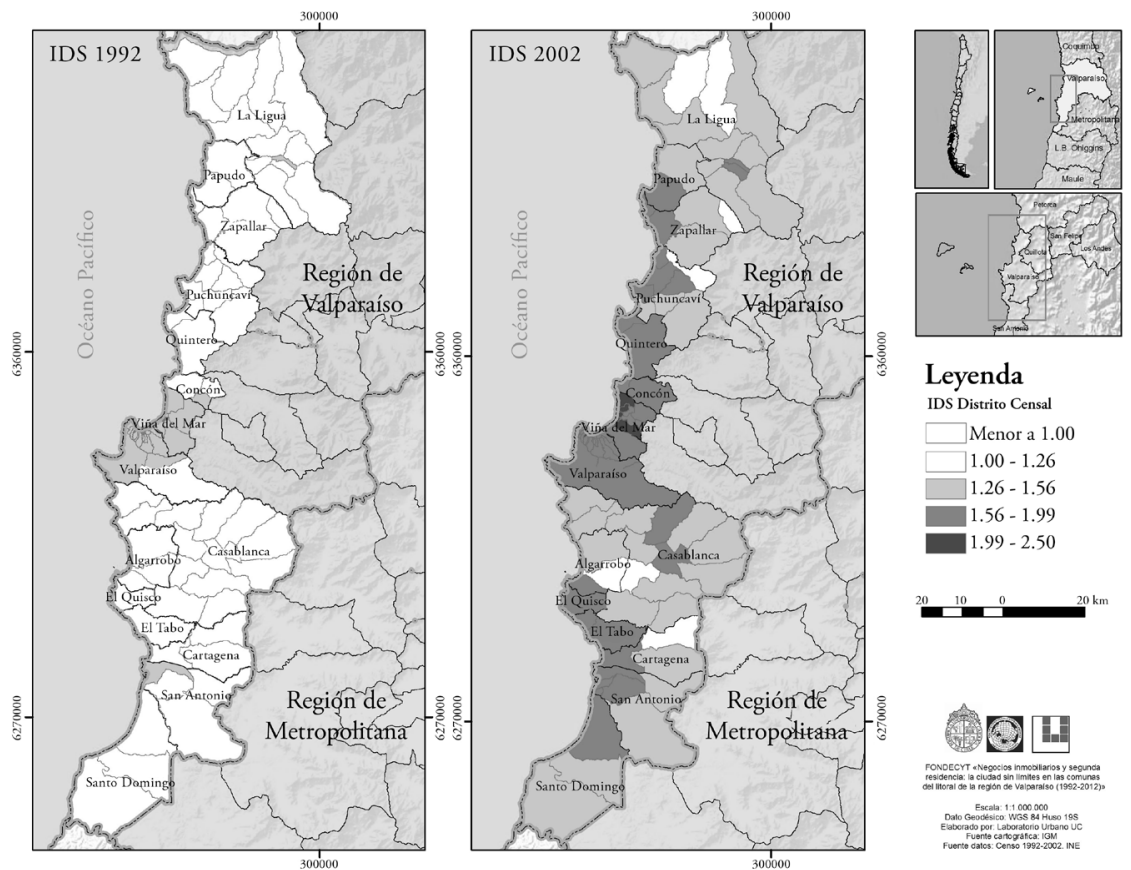

FUENTE ELABORACIÓN PROPIA CON DATOS DE LOS CENSOS DE POBLACión Y VIVIENDA (INSTITUTO NACIONAL DE ESTADÍSTICAS [INE], I 992; 2002)

El boom inmobiliario en el área de estudio ha contribuido a una mayor extensión de las manchas urbanas, que han contribuido no solo a incrementar las superficies construidas en comunas que eran predominantemente rurales hasta comienzos de la década de los noventa, sino también a extender las áreas conurbadas en más de un $1.000 \%$ en Petorca, $122 \%$ en San Antonio, y en menor medida en el Área Metropolitana de Valparaíso, con un 53\% entre 1992 y 2011. Por lo tanto, la mayor ocupación del espacio litoral, junto a las frágiles condiciones de equilibrio dinámico de los procesos de sedimentación costera y de articulación sistémica entre las dunas y la playa, así como el papel de las primeras para la conservación de la vegetación y avifauna local, son fuente de graves procesos de degradación ambiental. Aunque se promocionen como utópolis para hogares de clases altas y medias, el efecto socioespacial agregado las convierte en distópolis. 


\section{Conclusiones}

El análisis realizado da cuenta de cómo la producción inmobiliaria, en este caso de utópolis / distópolis en el borde costero, es una actividad indisociable de la generación de signos y símbolos (Lefebvre, 2013). Es mediante la movilización, estimulación e incluso manipulación de tramas de significados o imaginarios (Hiernaux, 2007; 2009; Hiernaux, Hidalgo, Santana \& Arenas, 2015) y la proyección ficticia de utopías urbanas, que se impulsan, en parte, las dinámicas materiales de acumulación de capital en sectores inmobiliarios que operan actualmente con una mayor capacidad cuantitativa y cualitativa para extender lo urbano incluso más allá de la ciudad.

A diferencia de la promoción de utópolis y la construcción de distópolis en otros espacios costeros, el litoral central de Chile ha sido incorporado, mediante la compresión del espacio-tiempo metropolitano, a la macrozona urbana. Aunque el rol de la segunda residencia fue fundamental hasta finales de los noventa para extender el tejido urbano en la región, durante la última década las utópolis / distópolis han asumido también una función de vivienda principal, asociada a flujos migratorios por amenidades. Y aunque estos procesos han introducido importantes modificaciones en las geografías sociales en cuanto a la elitización de ciertos lugares, dichos cambios no presentan un carácter tan transnacional como lo ocurrido en España o en ciertos países de Centroamérica.

A pesar de las particularidades del caso de estudio, la promoción de utópolis por los agentes inmobiliarios locales presenta las mismas características distópicas que se dan en otros ámbitos iberoamericano: las condiciones de sitio propias de los espacios litorales son vendidas a precios de monopolio, intensificando la especulación inmobiliaria en comunas del norte y en menor medida en las del sur; la desregulación en materia territorial y ambiental ha propiciado la acelerada extensión de manchas urbanas sobre ecosistemas frágiles; y parece existir una mayor segregación y fragmentación social. Por lo tanto, no solo es preciso ampliar los análisis respecto a estos efectos distópicos a escala local, sino profundizar en las estrategias socioespaciales multiescalares emprendidas por los agentes del ahora reestructurado sector inmobiliario chileno.

\section{Referencias bibliográficas}

Andrade, B. \& Hidalgo, R. (1996). Desarrollo urbano en el litoral de la Provincia de Petorca: una aproximación desde los instrumentos de planificación territorial y la fragilidad del medio físico. Revista de Geografía Norte Grande, (24), 157-164. Disponible en http:// www.icp.puc.cl/laburb/investigacion/sistnat/d_urbano_provinciapetorca.pdf

Babinger, F. (2012). El turismo ante el reto de peligros naturales recurrentes: una visión desde Cancún. Investigaciones Geográficas. Boletín del Instituto de Geografía UNAM, (78), 7588. doi: http://dx.doi.org/10.14350/rig.32471

Baños, J. (2012). Ocupación del territorio litoral en ciudades turísticas de México. Bitácora Territorial, 20(1), 41-52. Disponible en http://www.redalyc.org/articulo. oa?id=74824041005 
Brenner, N. (2013). Tesis sobre la urbanización planetaria. Revista Nueva Sociedad, (243) (enerofebrero), 38-66. Disponible en http://nuso.org/articulo/tesis-sobre-la-urbanizacionplanetaria/

Bin, O. \& Brown, J. (2006). Real estate market response to coastal flood hazards. Natural Hazards Review, 7(4), 137-144. http://dx.doi.org/10.1061/(ASCE)1527-6988(2006)7:4(137)

Bin, O., Poulter, B., Dumas, C. \& Whitehead, J. (2011). Measuring the impact of sea-level rise on coastal real estate: A hedonic property model approach. Journal of Regional Science, 51(4), 751-767. doi: 10.1111/j.1467-9787.2010.00706.x

Borsdorf, A. \& Hidalgo, R. (2013). Mountains and the sea: An analysis of the 2010 real estate and retail sectors in the Metropolitan Region of Valparaíso-Viña del Mar, Chile. Mountain Research and Development, 33(3), 332-338. http://dx.doi.org/10.1659/ MRD-JOURNAL-D-11-00080.1

Cáceres, G. \& Sabatini, F. (2003). Para entender la urbanización del litoral: el balneario en la conformación del Gran Valparaíso (siglos xIx y xx). AEQ (Santiago), (55), 50-52. http://dx.doi.org/10.4067/S0717-69962003005500013

Capel, H. (2013). La morfología de las ciudades. Tomo III: Agentes urbanos y mercado inmobiliario. Barcelona: Ediciones del Serbal.

Capel, H. (1982). Filosofía y ciencia en la geografía contemporánea. Una introducción a la geografía. Barcelona: Barcanova.

Castro, C. \& Hidalgo, R. (2002). Del pueblo balneario a la gran conurbación: la expansión urbana en el litoral central de la v Región de Valparaíso, Provincia de San Antonio, 1954-2000. Revista Geográfica de Valparaíso, (32-33), 91-103.

Cattaneo, R. (2011). Los fondos de inversión inmobiliaria y la producción privada de vivienda en Santiago de Chile: ¿un nuevo paso hacia la financiarización de la ciudad? EURE, 37(112), 5-22. Disponible en http://www.scielo.cl/pdf/eure/v37n112/art01.pdf

Chaparro, J. \& Santana, D. (2013). Institucionalización del turismo internacional en Cartagena de Indias, Colombia: aspectos político-económicos, actores centrales y mercado laboral (2000-2010). En I. Duque (Ed.), Historiografía y planificación urbana (pp. 343-381). Bogotá: Universidad Nacional de Colombia.

Ciccolella, P. \& Mignaqui, I. (2009). Capitalismo global y transformaciones metropolitanas: enfoques e instrumentos para repensar el desarrollo urbano. En H. Poggiese \& T. Cohen (Eds.), Otro desarrollo urbano. Ciudad incluyente, justicia social y gestión democrática (pp. 35-50). Buenos Aires: Consejo Latinoamericano de Ciencias Sociales (CLACso). Disponible en http://biblioteca.clacso.edu.ar/clacso/formacionvirtual/20100817111051/poggiese.pdf

Colburn, L. \& Jepson, M. (2012). Social indicators of gentrification pressure in fishing communities: A context for social impact assessment. Coastal Management, 40(3), 289-300. doi: 10.1080/08920753.2012.677635

Collins, D. (2013). Gentrification or 'multiplication of the suburbs'? Residential development in New Zealand's coastal countryside. Environment and Planning A, 25, 109-125. doi: $10.1068 / \mathrm{a} 4571$

Cuervo, L. M. \& González, J. (1997). Industria y ciudades en la era de la mundialización, un enfoque socioespacial. Bogotá: Tercer Mundo Editores-Colciencias. 
Delgado, C. (2008). Urbanización sin fronteras. El acoso urbanístico a los espacios naturales protegidos. Boletín de la Asociación de Geógrafos Españoles, (47), 271-310. Disponible en http://dialnet.unirioja.es/servlet/articulo?codigo $=3093618$

Delgado, O. (2003). Debates sobre el espacio en la geografía contemporánea. Bogotá: Universidad Nacional de Colombia.

De Mattos, C. (2013). Reestructuración económica y metamorfosis en América Latina: de la ciudad a la región urbana. En J. Noyola, C. de Mattos \& A. Orellana (Eds.), Urbanización en tiempos de crisis. Impactos, desafios y propuestas (pp. 13-43). Santiago de Chile: Universidad Autónoma de Nuevo León (unnL), México / Facultad de Arquitectura (FArQ), Uruguay / Instituto de Estudios Urbanos y Territoriales, P. Universidad Católica de Chile.

De Mattos, C. (2011). Santiago de Chile, de ciudad a región urbana. En C. de Mattos, L. Wiley Ludeña \& L. Fuentes (Eds.), Lima-Santiago. Reestructuración y cambio metropolitano (pp. 181-208). Lima: Centro de Investigación de la Arquitectura y la Ciudad, Pontificia Universidad Católica del Perú / Santiago: Instituto de Estudios Urbanos y Territoriales, Pontificia Universidad Católica de Chile.

De Mattos, C. (2010). Globalización y metamorfosis urbana en América Latina. Quito: Organización Latinoamericana y del Caribe de Centros Históricos (OLACCHI) / Municipio del Distrito Metropolitano de Quito (MDMQ).

De Mattos, C. (2002). Transformación de las ciudades latinoamericanas: ¿impactos de la globalización? EURE, 28(85), 1-10. http://dx.doi.org/10.4067/S025071612002008500001

Dollfus, O. (1978). El análisis geográfico. Barcelona: Oikos-Tau.

EBCO, S.A. (2014). Obras en ejecución centro. Recuperado en julio de 2014 de http://www. ebco.cl/proyectos-centro/

Freeman, C. \& Cheyne, C. (2008). Coasts for sale: Gentrification in New Zealand. Planning Theory \& Practice, 9(1), 33-56. doi: 10.1080/14649350701843846

Gaja, F. (2008). El "tsunami urbanizador" en el litoral mediterráneo. El ciclo de hiperproducción inmobiliaria 1996-2006. Scripta Nova. Revista Electrónica de Geografía y Ciencias Sociales, 12(270). Disponible en http://www.ub.edu/geocrit/sn/sn-270/sn-270-66.htm

George, P. (1969). Geografia urbana. Barcelona: Ariel.

Gil de Lamadrid, R. (2008). Deluxe squatters in Puerto Rico: The case of la Parguera's Casetas. Centro Journal, 20(2), 70-91.

González, R. (2011). Los procesos de migración de amenidad y la competitividad de destinos turísticos de montaña del oeste canadiense y de la norpatagonia argentina. Estudios y Perspectivas en Turismo, 20(5), 1102-1122. Disponible en http://www.redalyc.org/ articulo.oa?id $=180722704008$

Gray, de Cerdán, N. (1987). Territorio y urbanismo: bases para una geografia prospectiva. Mendoza: Consejo Nacional de Investigaciones Científicas y Técnicas (CONICET).

Griffith, D. (2000). Social capital and economic apartheid along the coasts of the Americas. Urban Anthropology, 29(3), 255-284.

Gottdiener, M. (1994). The social production of urban space. Austin: University of Texas Press.

Harvey, D. (1991). Los límites del capitalismo y la teoría marxista. México: Fondo de Cultura Económica.

Harvey, D. (2011). Espaços de Esperança. São Paulo: Edições Loyola. 
Harvey, D. (2013). Ciudades rebeldes. Del derecho a la ciudad a la revolución urbana. Madrid: Akal.

Hidalgo, R. (2004). De los pequeños condominios a la ciudad vallada: las urbanizaciones cerradas y la nueva geografía social (1990-2000). EURE, 91(30), 29-52. http://dx.doi. org/10.4067/S0250-71612004009100003

Hidalgo, R. (2013). La transformación de las áreas centrales en América Latina: agentes inmobiliarios y nueva morfología urbana en el caso de Santiago de Chile. En Paulo Pereira (Ed), Negócios imobiliários e transformaçóes sócio-territoriais em cidades da América Latina (pp. 23-31). São Paulo: Conselho Nacional de Desenvolvimento Científico e Tecnológico (CNPQ), Universidade de São Paulo / Pontificia Universidad Católica de Chile / Comisión Nacional de Investigación Científica y Tecnológica CONICYT), Chile.

Hidalgo, R. \& Arenas, F. (2012). Negocios inmobiliarios en el frente litoral del Área Metropolitana de Valparaíso (AMv): entre la (des)protección del medio natural y la conservación del patrimonio cultural de la unesco. Scripta Nova. Revista Electrónica de Geografia y Ciencias Sociales, 16(418) Disponible en http://www.ub.edu/geocrit/sn/ sn-418/sn-418-46.htm

Hidalgo, R., Arenas F., Sánchez, R. \& Wolker, P. (2014). La macrozona urbana central chilena. Dudas sobre su sostenibilidad y vulnerabilidad. En P. Brand, R. Hidalgo, J. Montoya \& L. Pérez (Eds.), Metropolizaciones Colombia-Chile: experiencias en Concepción, Medellín, Bogotá y Santiago (pp. 11-26). Medellín: Universidad Nacional de Colombia.

Hidalgo, R. \& Borsdorf, A. (2009). El crecimiento urbano en Europa: conceptos, tendencias y marco comparativo para el área metropolitana de Santiago de Chile. Estudios Geográficos, 70(266) ,181-203. doi: 10.3989/estgeogr.0449

Hidalgo, R., Borsdorf, A. \& Sánchez, R. (2005). La expansión residencial amurallada en la configuración metropolitana de Santiago de Chile. En C. de Mattos \& R. Hidalgo (Eds.), Santiago de Chile. Movilidad espacial y reconfiguración metropolitana (pp. 117136). Santiago de Chile: Geolibros, Instituto de Estudios Urbanos y Territoriales (IEUT), Eure Libros.

Hidalgo, R., Borsdorf, A. \& San Martín, G. (2013). Socio-spatial change in the world heritage site Valparaíso. Die Erde. Journal of the Geographical Society of Berlin, 144(3), 105-116. Disponible en http://www.die-erde.org/index.php/die-erde/article/view/127

Hidalgo, R., Borsdorf, A. \& Zunino, H. (2008). Las dos caras de la expansión residencial en la periferia metropolitana de Santiago de Chile: precariópolis estatal y privatópolis inmobiliaria. En P. Pereira \& R. Hidalgo (Eds.), Producción inmobiliaria y reestructuración metropolitana en América Latina (pp. 167-190). Santiago de Chile: Faculdade de Arquitetura e Urbanismo, Universidade de São Paulo (FAUSP-Usp) / Pontificia Universidad Católica de Chile.

Hidalgo. R. \& Janoschka, M. (Eds). (2014). La ciudad neoliberal. Gentrificación y exclusión en Santiago de Chile, Buenos Aires, Ciudad de México y Madrid. Santiago: Pontificia Universidad Católica de Chile. 
Hidalgo, R., Volker, P. \& Ramírez, N. (2014). La ciudad inmobiliaria: mecanismos institucionales, relaciones de poder y mercantilización del medio natural. El caso del Área Metropolitana de Valparaíso. Ponencia presentada al xv Coloquio Internacional de Geocritica, Barcelona, Universidad de Barcelona, 5 al 10 de mayo. Disponible en http://www.ub.edu/geocrit/coloquio2014/Hidalgo\%20Volker\%20Ramirez.pdf

Hiernaux, D. (2007). Los imaginarios urbanos: de la teoría y los aterrizajes en los estudios urbanos. EURE, 33(99), 17-30. http://dx.doi.org/10.4067/S0250-71612007000200003

Hiernaux, D. (2009). Los imaginarios del turismo residencial: experiencias mexicanas. En T. Mazón, R. Huete \& A. Mantecón (Eds.), Turismo, urbanización y estilos de vida. Las nuevas formas de movilidad residencial (pp. 109-125). Barcelona: Icaria.

Hiernaux, D., Hidalgo, R., Santana, D. \& Arenas, F. (2015). Produciendo urbanización en el litoral de la región de Valparaíso: imaginarios y producción inmobiliaria. En D.Hiernaux (Coord.), Turismo, sociedad y territorio: una lectura critica (pp. 327-346). Querétaro: Universidad de Querétaro.

Jiménez, A. \& Sosa, A. (2010). El turismo de segundas residencias en Cancún y la Riviera Maya: una visión panorámica de su evolución al inicio del milenio. En D. Hiernaux (Ed.), Las segundas residencias en México: un balance (pp. 37-95). México D.F.: Plaza y Valdés.

Kahn, M., Vaughn, R. \& Zasloff, J. (2010). The housing market effects of discrete land use regulations: Evidence from the California coastal boundary zone. Journal of Housing Economics, (19), 269-279. Disponible en http://ssrn.com/abstract=1758096

Huete, R. (2007). El desarrollo turístico residencial: propuesta desde la experiencia mediterránea. viI Jornadas de Sociología. Pasado, Presente y Futuro. Buenos Aires: Universidad de Buenos Aires.

Instituto Nacional de Estadísticas (INE) (1992). Censo de Población y Vivienda. Disponible en http://www.ine.cl/canales/chile_estadistico/censos/censo_poblacion_vivienda.php

Instituto Nacional de Estadísticas (INE) (2002). Censo de Población y Vivienda. Disponible en http://www.ine.cl/canales/chile_estadistico/censos/censo_poblacion_vivienda.php

Inmobiliaria Wood (2014). Recuperado en julio de 2014 en http://www.iwood.cl/casas/ cachagua/proyecto-7478f53515d6cd2d8fb8e7e5b1639f33.html\#

Janoschka, M. (2013). Nuevas geografías migratorias en América Latina: prácticas de ciudadanía en un destino de turismo residencial. Scripta Nova. Revista Electrónica de Geografía y Ciencias Sociales, 17(439). Disponible en http://www.ub.edu/geocrit/sn/sn-439.htm

Kondo, M., Rivera, R. \& Rullman, S. (2012). Protecting the idyll but not the environment: second homes, amenity migration and rural exclusion in Washington State. Landscape and urban planning, 106(2), 174-182. http://dx.doi.org/10.1016/j. landurbplan.2012.03.003

Lefebvre, H. (1970). Lógica formal, lógica dialéctica. Madrid: Siglo xxi.

Lefebvre, H. (1980). La revolución urbana (3a ed.). Madrid: Alianza Editorial.

Lefebvre, H. (2013). La producción del espacio. Madrid: Capitán Swing. 
Lencioni, S. (2011). Referencias analíticas para a discussão da metamorfose metropolitana. En S. Lencioni, S. Vidal-Koppmann, R. Hidalgo \& P. Pereira, Transformaçôes sócioterritoriais nas metrópoles de Buenos Aires, São Paulo e Santiago (pp. 51-60). São Paulo: Universidade de São Paulo / Pontificia Universidad Católica de Chile / Consejo Nacional de Investigaciones Científicas y Técnicas (CONICET), Argentina / Conselho Nacional de Desenvolvimento Científico e Tecnológico (CNPQ).

Lencioni, S. (2014). Reestruturação imobiliária: uma análise dos processos de concentração e centralização do capital no setor imobiliário. EURE, 40(120), 29-47. http://dx.doi. org/10.4067/S0250-71612014000200002

Mantecón, A. 2011. El proceso del turismo residencial. Análisis sociopolítico de los discursos públicos desde una perspectiva cualitativa. EMPIRIA. Revista de Metodología de Ciencias Sociales, (21), 17-38. Disponible en http://www.redalyc.org/articulo. oa?id=297124020001

McNamara, D. 2013. A coupled physical and economic model of the response of coastal real estate to climate risk. Nature Climate Change, 3(6), 559-562. doi:10.1038/ nclimate1826

Ministerio de Desarrollo Social (2011). Encuesta Casen. Recuperado en julio de 2014 en http://observatorio.ministeriodesarrollosocial.gob.cl/casen_obj.php

Ministerio de Obras Públicas (MOP) (2014). Centro de documentación. Recuperado en julio de 2014 en http://www.mop.cl/CentrodeDocumentacion/Paginas/default.aspx

Morales, E. \& Allesch, R. (Coord.). (1996). Geografía de Chile. Geografía V Región de Valparaíso. Santiago de Chile: Instituto Geográfico Militar.

Morales, S. \& Rainer, G. (2013). Migración por amenidad y turismo: ¿¿dinámicas globales en el espacio rural? El caso de Tafí del Valle (Tucumán, Argentina). Pasos. Revista de Turismo y Patrimonio Cultural, 11(4), 571-582. Disponible en http://www.pasosonline.org/ articulos/638-114

Moura, R. (2011). Arranjos urbano-regionais no Brasil: especificidades e reprodução de padrōes. Biblio 3W. Revista Bibliográfica de Geografía y Ciencias Sociales, 16(923). Disponible en http://www.ub.es/geocrit/b3w-923.htm

Papudo Laguna (2014). Recuperado en julio de 2014 en http://papudolaguna.cl/

Pereira, P. (2008). Produção imobiliária e crise da cidade na emergência de uma nova forma de metrópole na América Latina. En P. Pereira \& R. Hidalgo (Eds.), Producción inmobiliaria y reestructuración metropolitana en América Latina (pp. 55-65). Santiago de Chile: Faculdade de Arquitetura e Urbanismo, Universidade de Sáo Paulo (fauspusp) / Pontificia Universidad Católica de Chile.

Pereira, P. (2013). Agentes imobiliários, e reestruturação: interesses e conflictos na construção da cidade contemporânea. En P. Pereira (Ed.), Negócios imobiliários e transformaçôes sócio-territoriais em cidades da América Latina (pp. 23-31). São Paulo: CNPQ-USP-PUCCONICIT.

Portal Inmobiliario. (2014). Recuperado en julio de 2014 en http://www.portalinmobiliario. com/

Romero, J. L. (2007). Latinoamérica. Las ciudades y las ideas. Buenos Aires: Siglo XxI Editores. 
Romero, J., Jiménez, F. \& Villoria, M. (2012). (Un)sustainable territories: Causes of the speculative bubble in Spain (1996-2010) and its territorial, environmental, and sociopolitical consequences. Environment and Planning C: Government and Policy, 30(3), 467-486. doi: 10.1068/c11193r

Sánchez, A. \& Cárdenas, C. (2000). El impacto de los proyectos inmobiliarios en el desarrollo local: el borde costero de la localidad de Horcón, Región de Valparaíso. Revista de Geografia de Norte Grande, (27), 111-121.

Santana, D. (2013). Precariópolis y privatópolis en la región metropolitana de Bogotá (1990-2010). Un análisis socioespacial de los barrios cerrados (Tesis de Maestría). Departamento de Geografía, Universidad Nacional de Colombia.

Silva de Oliveira, K. (2009). Condomínios fechados, residências secundárias e o uso do espaço público pelo capital imobiliário. Revista Acadêmica do Observatório de Inovação do Turismo, 4(1), 1-15. Disponible en http://bibliotecadigital.fgv.br/ojs/index.php/oit/ article/viewFile/5738/4449

Smith, N. 2012. La nueva frontera urbana. Ciudad revanchista y gentrificación. Madrid: Traficantes de Sueños.

Soja, E. 2008. Postmetrópolis. Estudios críticos sobre las ciudades y las regiones. Madrid: Traficantes de sueños.

Valdebenito, C. (2014). La huella socioeconómica y demográfica en la estructura residencial de las ciudades medias de Latinoamérica: el caso de Viña del Mar-Chile en la década 1992-2002. Scripta Nova. Revista Electrónica de Geografia y Ciencias Sociales, 38(492). Disponible en http://www.ub.es/geocrit/sn/sn-492.htm

Williams, R. 2001. El campo y la ciudad. Buenos Aires: Paidós. 